\title{
REVIEW
}

\section{Mission impossible? Urological management of patients with spinal cord injury during pregnancy: a systematic review}

\author{
J Pannek ${ }^{1}$ and S Bertschy ${ }^{2,3}$ \\ ${ }^{1}$ Department of Neuro-Urology, Swiss Paraplegic Center, Nottwil, Switzerland; ${ }^{2}$ Swiss Paraplegic Research (SPF), Nottwil, Switzerland \\ and ${ }^{3}$ Department of Health Sciences and Health Policy, University of Lucerne and SPF, Nottwil, Switzerland
}

\begin{abstract}
Study design: A systematic literature review.
Objectives: To systematically assess the existing knowledge about treatment of neurogenic lower urinary tract dysfunction (NLUTD) in pregnant women with traumatic spinal cord injury (SCl), as urologic management of these patients is mandatory, but no guidelines are available.

Setting: Paraplegic center in Switzerland.

Methods: Studies were identified by electronic search of PubMed and MedLine. Data were pooled and analyzed quantitatively.

Results: The evidence level of all 14 reports (163 patients, 226 pregnancies) included was low. In 13 studies, information was gathered by a retrospective review of the medical records or by questionnaires. In all studies, reported data were incomplete. SCI was cervical in $34.7 \%$, thoracic in $61.2 \%$ and lumbar in $4.1 \%$ of the pregnant women. In all $34.7 \%$ of the women used indwelling catheters, $25 \%$ performed intermittent catheterization, $11.5 \%$ used the Credé maneuver and $28.8 \%$ voided spontaneously. A total of $64 \%$ of the patients had at least one symptomatic urinary tract infection (UTI) during pregnancy. UTIs were more common in women with indwelling catheters $(100 \%)$ than in those performing intermittent catheterization (38.5\%), using the Credé technique (17\%) or voiding spontaneously $(53.3 \%)$. One study demonstrated a significant reduction in UTI during pregnancy without complications in mothers or infants.

Conclusion: No evidence-based recommendations can be drawn from the existing literature to guide urologists in the management of NLUTD in pregnant women with SCI. The number of studies is small, and data acquisition and presentation are often inadequate. Thus, further research is urgently needed. Spinal Cord (2011) 49, 1028-1032; doi:10.1038/sc.2011.66; published online 14 June 2011
\end{abstract}

Keywords: neurogenic lower urinary tract dysfunction; spinal cord injury; urinary tract infection; pregnancy; systematic literature review

\section{Introduction}

A traumatic spinal cord injury (SCI) does not impair fertility in women. Following a phase of amenorrhea that occurs in about a third of patients after acute SCI, lasts for about 4 months, and is presumed to be due to a temporary rise in prolactin, reoccurrence of ovulation can be demonstrated, re-establishing the possibility of becoming pregnant for women with SCI. ${ }^{1}$

Virtually all patients with a SCI suffer from neurogenic lower urinary tract dysfunction (NLUTD). ${ }^{2}$ The major aim of treatment of these patients is the preservation of renal function. An elevated storage pressure, either due to low bladder compliance or due to neurogenic detrusor over-

Correspondence: Professor J Pannek, Chefarzt Neuro-Urologie, Schweizer Paraplegiker-Zentrum, Guido A. Zäch Strasse 1, Nottwil, CH 6207, Switzerland.

E-mail: juergen.pannek@paranet.ch

Received 1 February 2011; revised 6 May 2011; accepted 10 May 2011; published online 14 June 2011 activity, is the major risk factor for renal deterioration. ${ }^{3}$ Therefore, the primary objective of bladder management is to achieve low-pressure urine storage and bladder emptying. ${ }^{4}$ The majority of patients with SCI need regular urologic evaluations and treatment of their bladder dysfunction. ${ }^{5}$

Urinary incontinence and urinary tract infections (UTIs) occur frequently in this group of patients. UTIs are the leading cause of septicemia in patients with spinal cord lesions, and are associated with a significantly increased mortality. ${ }^{6}$ Pregnancy is known to have an impact on the lower urinary tract in neurologically intact women. The risk for bacteriuria, for example, is elevated in pregnant women. ${ }^{7}$ Thus, pregnant women with SCI intuitively should be a high-risk group for UTI.

Without doubt, pregnant women with SCI require urologic care. On the other hand, standard treatment of NLUTD may not be possible during pregnancy, as several drugs, for example, anticholinergic medication, are contraindicated in pregnant women. Therefore, we undertook a systematic 
literature review to assess the current knowledge of urologic management of pregnant women with SCI.

\section{Materials and methods}

Evidence acquisition

The systematic review was carried out according to the Preferred Reporting Items for Systematic Reviews and Metaanalyses statement. ${ }^{8}$ We systematically searched electronic databases (PubMed and Medline) for studies published in English or German on the urologic management of pregnant women with SCI (Table 1). No date restrictions were applied. Search terms were customized to each database and involved combining key word searches for a list of adjustment terms, terms describing NLUTD and the term construct to describe 'spinal cord injury'.

Abstracts of all identified studies were independently reviewed by the authors and studies reporting on the urologic management of pregnant women with NLUTD were reviewed in full text.

Data extraction

Data from eligible reports were extracted by the authors. Information from each study that was relevant to the research question and in line with inclusion criteria was extracted and tabulated. The extracted data comprised publication data, study type, level of evidence, number of patients, age, number of pregnancies, urologic management and outcome. The level of evidence and type of studies were classified according to the Oxford Center of Evidence-Based Medicine criteria (http://www.pdptoolkit.co.uk/Files/ebm/ cebm/Doing\%20ebm/levelsofevidencetable.htm).

Synthesis

The extracted data were analyzed quantitatively. The information regarding urologic management extracted from all reports available was pooled and descriptive statistics were performed.

\section{Statistics}

For statistical analyses, a statistics and graphics management system (STATA, Santa Monica, CA, USA) was used. Owing to the paucity of data, merely descriptive statistical analyses were performed.

\section{Results}

Overview

After removing duplicates, we retrieved 228 articles. An initial review of these records found that 187 did not address the research question. However, 41 were potentially relevant. Full versions of these articles were obtained and reviewed against inclusion criteria. Uncertainties with regard to whether a study met inclusion criteria were resolved through discussion between the authors. After reviewing all abstracts and the full text of any study reporting on the urologic management of pregnant women with NLUTD due to SCI,
Table 1 Search strategy

\begin{tabular}{|c|c|}
\hline 1 & Spinal cord \\
\hline 2 & Injur* \\
\hline 3 & Lesion \\
\hline 4 & Trauma* \\
\hline 5 & Damage* \\
\hline 6 & 2 OR 3 OR 4 OR 5 \\
\hline 7 & 1 AND 6 \\
\hline 8 & Tetrapleg* \\
\hline 9 & Parapleg* ${ }^{\star}$ \\
\hline 10 & Quadripleg* \\
\hline 11 & Quadrupleg* \\
\hline 12 & 8 OR 9 OR 10 OR 1 \\
\hline 13 & 12 OR 7 \\
\hline 14 & Pregnan* $[\mathrm{MeSH}]$ \\
\hline 15 & Pregnancy \\
\hline 16 & Motherhood \\
\hline 17 & Mother* \\
\hline 18 & Parent* \\
\hline 19 & 14 OR 15 OR 16 OR 18 \\
\hline 20 & 13 AND 19 \\
\hline 21 & Women [MeSH] \\
\hline 22 & Woman \\
\hline 23 & Female \\
\hline 24 & 21 OR 22 OR 23 \\
\hline 25 & 20 AND 24 \\
\hline 26 & Neurogenic lower urinary tract dysfunction \\
\hline 27 & Neurogenic bladder \\
\hline 28 & Detrusor overactivity \\
\hline 29 & Detrusor hyperreflexia \\
\hline 30 & Detrusor sphincter dysynergia \\
\hline 31 & Urinary retention \\
\hline 32 & Urinary bladder \\
\hline 33 & 26 OR 27 OR 28 OR 29 OR 30 OR 31 OR 32 \\
\hline 34 & 33 AND 25 \\
\hline 35 & Urinary tract infection \\
\hline 36 & 25 AND 35 \\
\hline 37 & Electric stimulation therapy $[\mathrm{MeSH}]$ \\
\hline 38 & Sacral nerve stimulation \\
\hline 39 & Sacral neuromodulation \\
\hline 40 & 37 OR 38 OR 39 \\
\hline 41 & 25 AND 40 \\
\hline 42 & Sacral deafferentation \\
\hline 43 & SARS/SDAF \\
\hline 44 & Anterior root stimulation \\
\hline 45 & Brindley \\
\hline 46 & 42 OR 43 OR 44 OR 45 \\
\hline 47 & 25 AND 46 \\
\hline 48 & Anticholinergic* \\
\hline 49 & Antimuscarinic* \\
\hline 50 & 48 OR 49 \\
\hline 51 & 25 AND 50 \\
\hline 52 & Bladder augmentation \\
\hline 53 & lleum augmentation \\
\hline 54 & 52 OR 53 \\
\hline 55 & 25 AND 55 \\
\hline 56 & Botulinum toxin \\
\hline 57 & Botox \\
\hline 58 & 56 OR 57 \\
\hline 59 & 25 AND 5960 catheter* \\
\hline 61 & Intermittent \\
\hline 62 & Suprapubic \\
\hline 63 & Indwelling \\
\hline 64 & 60 OR 61 OR 62 OR 63 \\
\hline 65 & 25 AND 64 \\
\hline 66 & $\alpha$ blocker \\
\hline 67 & 25 AND 66 \\
\hline
\end{tabular}

15 publications were identified that matched the aforementioned criteria. One paper was a follow-up of a previous publication, including the entire study population of the 
initial publication. Thus, 14 articles identified through the search were ultimately included in the review (Figure 1).

\section{Study and patient characteristics}

The level of evidence of the included studies ranged from $2 b$ to 4 (Table 2). One was a prospective cohort study, ${ }^{22}$ nine were retrospective case series ${ }^{9-14,16,18,21}$ and four were case reports. ${ }^{15,17,19,20}$ In the case series and the case reports, information was gathered by a retrospective review of the medical records or by interviews of women with SCI who have borne children (Table 2).

Overall, 163 women with 226 pregnancies were enrolled. The number of pregnancies ranged from 1 to 5 , with an average of 1.4 pregnancies per woman. The mean age ranged from 20 to 34.66 years. The mean duration of the SCI was between 2.5 and 15.7 years. In all 34 patients had cervical lesions, 60 had thoracic injuries and 4 patients had lumbar lesions. In the remaining 65 patients, no information about the level of SCI was given. SCI was complete in 29 patients and incomplete in 22 patients; in 112 patients, no information about completeness of SCI was available.

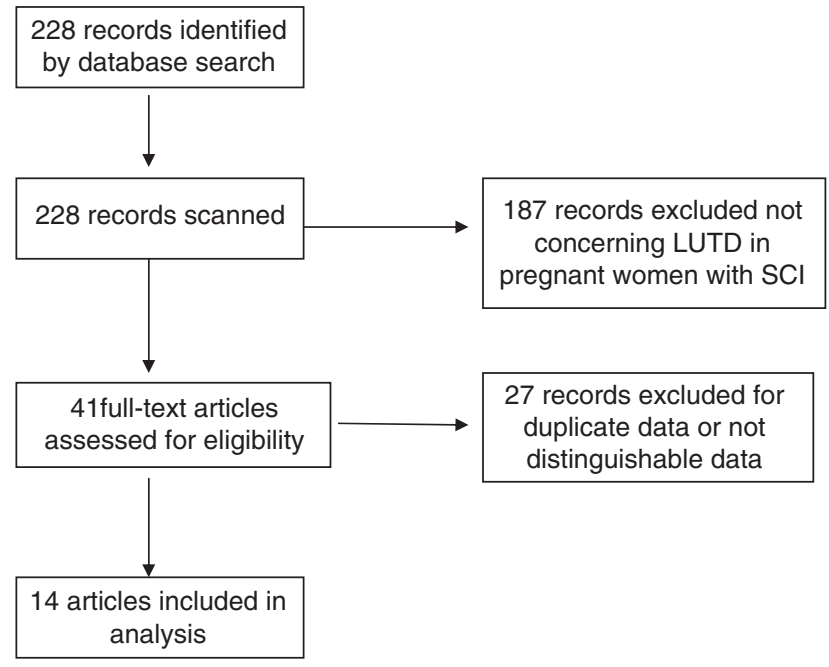

Figure 1 Diagram of the review process.

\section{Mode of bladder management}

In 52 women, the mode of bladder evacuation was described. Of these, 18 women (34.7\%) used indwelling (transurethral or suprapubic) catheters, 13 (25\%) performed intermittent catheterization, 6 (11.5\%) used the Credé maneuver and 15 (28.8\%) voided spontaneously.

\section{UTIS}

One case study based on retrospective patients' recollection stated that UTIs were more frequent in pregnancies post injury $(45.5 \%)$ than in pregnancies before SCI $(8.2 \%) .{ }^{13}$

In 10 reports covering 139 patients, data about UTIs were available. Of these, 89 (64\%) patients had at least one symptomatic UTI, leading to eight hospitalizations. In five cases, pyelonephritis was documented, and one case of septicemia leading to preterm labor was described. Recurrent UTIs were stated in 29 patients; four women suffered from chronic UTI. However, no clear-cut definitions were available for the terms 'UTI', 'recurrent UTI' and 'chronic UTI'. All UTIs required antibiotic treatment. In 15 patients, prophylactic antibiotic treatment was established. As neither indications for nor results of prophylactic antibiotic treatment were clearly stated, no conclusions regarding the usefulness of this treatment could be drawn.

One study with six patients prospectively evaluated the usefulness of a regimen called 'weekly oral cycling antibiotic'. The rate of UTI could be significantly reduced from 6 UTIs per patient per year before pregnancy to 0.4 UTI per patient per year during pregnancy without complications in mothers or infants. ${ }^{22}$

Correlation between mode of bladder evacuation and UTIs All 18 women with indwelling catheters experienced at least one UTI during pregnancy (100\%). Of the 13 women with intermittent catheterization, five patients developed UTI (38.5\%), whereas UTIs were reported in 1 of the 6 women performing the Credé technique (17\%) and in 8 of the 15 patients voiding spontaneously (53.3\%).

Table 2 Summary of the studies included in the review

\begin{tabular}{|c|c|c|c|c|c|}
\hline Study & Year of publication & $L O E$ & Study type & No. of patients & No. of pregnancies \\
\hline Baker et al. ${ }^{9}$ & 1992 & 4 & Retrospective case series & 11 & 13 \\
\hline Craig ${ }^{10}$ & 1990 & 4 & Retrospective case series & 9 & 13 \\
\hline Cross et al. ${ }^{11}$ & 1992 & 4 & Retrospective case series & 22 & 33 \\
\hline Feyi-Waboso ${ }^{12}$ & 1992 & 4 & Retrospective case series & 8 & 8 \\
\hline Jackson et al. ${ }^{13}$ & 1999 & 4 & Retrospective case series & 66 & 101 \\
\hline Kulkarni et al. ${ }^{14}$ & 1992 & 4 & Retrospective case series & 6 & 6 \\
\hline McGregor et al. ${ }^{15}$ & 1985 & 4 & Case report & 1 & 1 \\
\hline Rageth et al. ${ }^{16}$ & 1986 & 4 & Retrospective case series & 13 & 17 \\
\hline Rossier et al. ${ }^{17}$ & 1969 & 4 & Case report & 1 & 1 \\
\hline Skowronski et al. ${ }^{18}$ & 2008 & 4 & Retrospective case series & 5 & 7 \\
\hline Sziller et al..$^{19}$ & 1973 & 4 & Case report & 1 & 1 \\
\hline Tsoutsoplides ${ }^{20}$ & 1982 & 4 & Case report & 1 & 2 \\
\hline Wanner et al. ${ }^{21}$ & 1987 & 4 & Retrospective case series & 13 & 17 \\
\hline \multirow[t]{2}{*}{ Salomon et al. ${ }^{22}$} & 2009 & $2 b$ & Prospective cohort study & 6 & 6 \\
\hline & & & & 163 & 226 \\
\hline
\end{tabular}

Abbreviation: LoE, level of evidence. 


\section{Other urologic complications}

Quantifiable urologic complications described in the retrieved records were four bladder stones newly diagnosed during pregnancy. Other complications, such as incontinence, were mentioned, but not quantified. A single study with 66 patients, of which $40 \%$ had an indwelling catheter, reported leakage around the indwelling catheter in $15 \%$, bladder spasms being so significant that catheters were expelled in $9.1 \%$ and there was a necessity to change the mode of bladder management in $25 \%$. However, no details were reported.

\section{Discussion}

Despite the fact that an increasing number of women with SCI are biologically able to conceive children, the implications of pregnancy on urologic treatment in women with SCI have not yet been assessed in a systematic manner. We found that the level of evidence was low for all studies that addressed this issue. This is not surprising, as the number of pregnant women with SCI is rather low; therefore, a randomized prospective study with an adequate number of subjects is difficult to initiate. Furthermore, randomized prospective studies in pregnant women raise severe ethical concerns. However, it was surprising to us that the quality of the existing data was poor. Only a single study has been specifically designed to evaluate urologic problems during pregnancy. ${ }^{22}$ In all studies, documentation of even basic data, such as age, medical treatment of NLUTD, mode of bladder evacuation and level of injury, was incomplete. Only one study ${ }^{12}$ stated that the mode of bladder management remained unchanged during pregnancy. Thus, data regarding timing and rationale for the bladder management changes were lacking.

The data we retrieved mainly addressed the rate of UTI and the mode of bladder management. Based on the available data, however, no sound conclusions are possible. The rate of UTI during pregnancy in women with SCI seems to be rather high $(64 \%)$, but the validity of these data is hampered by the varying definitions of the term 'UTI'. As UTIs are known to be a risk factor for pyelonephritis and low birthweight, and a Cochrane review in pregnant women without SCI demonstrated that antibiotic treatment resulted in a reduced incidence of these complications, ${ }^{23}$ treatment of UTI in pregnant women with UTI should be considered, although treatment of asymptomatic bacteriuria is usually not indicated in patients with SCI. ${ }^{6}$

For prevention of UTI in pregnant women with UTI, a very small prospective case study suggests that using a weekly oral cycling antibiotic program may significantly reduce the incidence of UTI, ${ }^{22}$ but the data are not sufficient to allow an evidence-based recommendation.

Although the rate of UTI in women with indwelling catheters is higher than in those performing any other mode of bladder evacuation, the risks and benefits of indwelling catheterization during pregnancy in women with SCI cannot be answered based on the data of the review. Even though the lowest UTI rate was described in women using the Credè maneuver, owing to the small number of patients, it is not possible to give any evidence-based recommendation for the use of a certain bladder evacuation technique to reduce UTI rates.

The paucity of data is astonishing and disappointing indeed, as the number of women with SCI getting pregnant seems to be increasing. ${ }^{24}$ On one hand, it is evident that NLUTD needs to be treated to prevent secondary complications. ${ }^{4}$ On the other hand, it is well known that a large number of treatment options for lower urinary tract dysfunction are either contraindicated in pregnancy (for example, certain anticholinergic drugs), or their use has not been thoroughly studied in this condition.

For example, no data are available with regard to the safety of anterior root stimulation, a technique exclusively used in SCI patients, during pregnancy. Regarding botulinum toxin A, a questionnaire-based survey, including 16 women $^{25}$ and 4 additional case reports, ${ }^{26-29}$ described the use of botulinum toxin A treatment up to a dose of 300 i.u. Botox during pregnancy for various indications without noted complications for the patient or the child.

For sacral neuromodulation in pregnant women, only case studies with a small number of patients exist. In summary, it was advised to deactivate the device during pregnancy, but no negative implications of sacral neuromodulation on the course of the pregnancy have been described. ${ }^{30}$

For bladder augmentation, the largest case series comprised 15 pregnant women without SCI. In all 60\% of the patients suffered from pyelonephritis, but continence was preserved and pregnancies were possible without major adverse events. $^{31}$

One cannot draw any conclusions for the management of pregnant women with SCI based on these reports, as the specifics of patients with SCI are not taken into consideration. Therefore, well-designed clinical studies are needed to be able to adequately counsel pregnant women with SCI. Until today, it is virtually impossible to give any recommendations for the urologic management of women with SCI during pregnancy based on the results of a systematic literature review.

\section{Conflict of interest}

The authors declare no conflict of interest.

\section{References}

1 Reame NE. A prospective study of the menstrual cycle and spinal cord injury. Am J Phys Med Rehabil 1992; 71: 15-21.

2 de Groat WC, Kawatani M, Hisamitsu T, Cheng CL, Ma CP, Thor K et al. Mechanisms underlying the recovery of urinary bladder function following spinal cord injury. J Auton Nerv Syst 1990; 30 (Suppl): 71-77.

3 Gerridzen RG, Thijssen AM, Dehoux E. Risk factors for upper tract deterioration in chronic spinal cord injured patients. J Urol 1992; 147: $416-418$

4 Stöhrer M, Blok B, Castro-Diaz D, Chartier-Kastler E, Del Popolo $\mathrm{G}$, Kramer $\mathrm{G}$ et al. EAU guidelines on neurogenic lower urinary tract dysfunction. Eur Urol 2009; 56: 81-88.

5 Nosseir M, Hinkel A, Pannek J. Clinical usefulness of urodynamic assessment for maintenance of bladder function in patients with spinal cord injury. Neurourol Urodyn 2007; 26: 228-233. 
6 Biering-Sørensen F, Bagi P, Høiby N. Urinary tract infections in patients with spinal cord lesions: treatment and prevention. Drugs 2001; 61: 1275-1287.

7 Holroyd-Leduc JM, Straus SE. Management of urinary incontinence in women: scientific review. JAMA 2004; 291: 986-995.

8 Moher D, Liberati A, Tetzlaff J, Altman DG. Preferred reporting items for systematic reviews and meta-analyses: the PRISMA statement. PLoS Med 2009; 6: e1000097.

9 Baker ER, Cardenas DD, Benedetti TJ. Risks associated with pregnancy in spinal cord-injured women. Obstet Gynecol 1992; 80: $425-428$.

10 Craig DI. The adaptation to pregnancy of spinal cord injured women. Rehabil Nurs 1990; 15: 6-9.

11 Cross LL, Meythaler JM, Tuel SM, Cross AL. Pregnancy, labor and delivery post spinal cord injury. Paraplegia 1992; 30: 890-902.

12 Feyi-Waboso PA. An audit of five years' experience of pregnancy in spinal cord damaged women. A regional unit's experience and a review of the literature. Paraplegia 1992; 30: 631-635.

13 Jackson AB, Wadley V. A multicenter study of women's selfreported reproductive health after spinal cord injury. Arch Phys Med Rehabil 1999; 80: 1420-1428.

14 Kulkarni S, Morgan OS. Pregnancy outcome in paraplegic women. W Indian Med J 1992; 41: 99-100.

15 McGregor JA, Meeuwsen J. Autonomic hyperreflexia: a mortal danger for spinal cord-damaged women in labor. Am J Obstet Gynecol 1985; 151: 330-333.

16 Rageth JC, Wanner M, Iljazovic S, Heinzl S. Schwangerschaft, Geburt und Wochenbett bei Paraplegikerinnen. Geburtshilfe Frauenheilkd 1986; 46: 536-540.

17 Rossier AB, Ruffieux M, Ziegler WH. Pregnancy and labour in high traumatic spinal cord lesions. Paraplegia 1969; 7: 210-216.

18 Skowronski E, Hartman K. Obstetric management following traumatic tetraplegia: case series and literature review. Aust New Zeal J Obstet Gynaecol 2008; 48: 485-491.
19 Sziller O, Novoszel T. ber die Schwangerschaft und Entbindung gelähmter Frauen. Zentralblatt Gynakol 1973; 95: 1589-1594.

20 Tsoutsoplides GC. Pregnancy in paraplegia: a case report. Int J Gynaecol Obstet 1982; 20: 79-83.

21 Wanner MB, Rageth CJ, Zäch GA. Pregnancy and autonomic hyperreflexia in patients with spinal cord lesions. Paraplegia 1987; 25: 482-490.

22 Salomon J, Schnitzler A, Ville Y, Laffont I, Perronne C, Denys P et al. Prevention of urinary tract infection in six spinal cordinjured pregnant women who gave birth to seven children under a weekly oral cyclic antibiotic program. Int J Infect Dis 2009; 13: 399-402.

23 Smaill F, Vazquez JC. Antibiotics for asymptomatic bacteriuria in pregnancy. Cochrane Database Syst Rev 2007 CD000490.

24 Ghidini A, Simonson MR. Pregnancy after spinal cord injury: a review of the literature. Top Spinal Cord Inj Rehabil 2011; 16: 93-103.

25 Morgan JC, Iyer SS, Moser ET, Singer C, Sethi KD. Botulinum toxin A during pregnancy: a survey of treating physicians. J Neurol Neurosurg Psychiatry 2006; 77: 117-119.

26 Li Yim JF, Weir CR. Botulinum toxin and pregnancy-a cautionary tale. Strabismus 2010; 18: 65-66.

27 Wataganara T, Leelakusolvong S, Sunsaneevithayakul P, Vantanasiri C. Treatment of severe achalasia during pregnancy with esophagoscopic injection of botulinum toxin A: a case report. J Perinatol 2009; 29: 637-639.

28 De Oliveira Monteiro E. Botulinum toxin and pregnancy. Skinmed 2006; 5: 308.

29 Newman WJ, Davis TL, Padaliya BB, Covington CD, Gill CE, Abramovitch AL et al. Botulinum toxin type A therapy during pregnancy. Mov Disord 2004; 19: 1384-1385.

30 Wiseman OJ, v d Hombergh U, Koldewijn EL, Spinelli M, Siegel SW, Fowler CJ. Sacral neuromodulation and pregnancy. J Urol 2002; 167: 165-168.

31 Hill DE, Kramer SA. Management of pregnancy after augmentation cystoplasty. J Urol 1990; 144: 457-459. 